\title{
Analysis of Impact of an Annual Robotics Festival
}

\author{
Fanny Riedo, Julia Fink, Mariza Freire and Francesco Mondada
}

\begin{abstract}
For four years a robotics festival has taken place at the Ecole Polytechnique Fédérale de Lausanne (EPFL), in Switzerland. As the number of visitors has rapidly grown from a few thousands to a dozen thousands, it gives an opportunity to investigate who is attending this event and which impact can be obtained in terms of education and motivation toward understanding science and technology. In the 2011 edition of the festival, a large survey was carried out, collecting data from 3423 visitors. The analysis of the collected data gives an idea about the profile of the people attending the event and the key factors impacting the acceptance of science and technology. Findings show that people of all ages and especially children and families have been attracted. More men than women attended the festival and visitors tended to have completed higher education. Overall, people appreciated that the event gave them the opportunity to discover new things about robotics and some teenagers got encouraged to learn more about it. We conclude by presenting our lessons learned and make suggestions to help others with organizing public robotic events.
\end{abstract}

\section{INTRODUCTION}

The growing role of technology in our society and the decreasing number of students engaging in engineering studies are two good arguments for better promoting science and technology among the general public. Robotics, because of its interdisciplinary nature and the fascination it generates among the large public, is a very interesting tool for education about science and technology. There are several types of events based on robotics:

- Permanent and temporary exhibitions. While some are interactive or have associated workshops, their central activity is based on exhibiting robotics systems [1], [2].

- Robotic contests. This type of competition exists at several levels, from children in primary school, up to contests among researchers. These competitions strongly involve the participants, but attract few visitors, basically parents and friends of the participants. This type of robotic event is the most current [3], [4], [5], [6].

- Open doors. These are events related to scientific institutions who want to show their activities. They usually attract a large audience and exploit the visibility of the related institution. On the other side, the people exhibiting are not communication or education professionals and the impact on the visitors is often limited.

- Festivals. These are very heterogeneous events, involving a huge variety of activities. They can be organized

This research was supported by the Swiss National Science Foundation through the National Centre of Competence in Research Robotics

F. Mondada, M. Freire and F. Riedo are with the Laboratory of Robotic Systems, Ecole Polytechnique Fédérale de Lausanne, Switzerland firstname. lastnamedepfl.ch

J. Fink is with the CRAFT lab, Ecole Polytechnique Fédérale de Lausanne, Switzerland firstname. lastnamedepfl.ch
TABLE I: Evolution of the number of visitors over the first four editions of the EPFL robotics festival.

\begin{tabular}{lllll}
\hline Year & $\begin{array}{l}\text { Visitors } \\
\text { estimation }\end{array}$ & Exhibits & $\begin{array}{l}\text { Visitors } \\
\text { to shows }\end{array}$ & $\begin{array}{l}\text { Visitors to } \\
\text { workshops }\end{array}$ \\
\hline 2008 & $3^{\prime} 000^{*}$ & 8 & $700^{*}$ & 581 \\
2009 & $5^{\prime} 000^{*}$ & 19 & $800^{*}$ & 1320 \\
2010 (two days) & $15^{\prime} 000^{*}$ & 25 & 5265 & 1848 \\
2011 & $13^{\prime} 000^{*}$ & 28 & 2520 & 1850 \\
\hline
\end{tabular}

by scientific institutions or by others actors within society. They can cover a strictly given topic but are often broader. Contrary to open doors, they can feature demonstrations by external actors [7], [6].

The last model, because of its flexibility, adaptation to societal issues and to various interests among the general public, has the potential to reach a wide audience and has been adopted in 2008 at the Ecole Polytechnique Fédérale de Lausanne (EPFL).

\section{The EPFL robotics festival}

In 2008, EPFL had an existing set of disconnected outreach activities based on robotics. To increase their visibility and impact, it was decided to group them into a free, single day event for the large public. The resulting event consists of three main activities:

- Exhibitions: Interactive live demonstrations of robots developed by EPFL, but also by other schools, associations, private people or companies ready to be active in this type of educational activity. Those exhibits are spread throughout the whole area of the festival.

- Workshops: Specific workshops for children of different ages with a special purpose and educational goal. Children can book a place in a workshop, for which durations range from 15 minutes to 3 hours depending on the activity. Topics covered include technical skills like soldering or programming, as well as more creative robotic system construction and investigative product disassembling.

- Shows: On stage performance in a large auditorium. Shows allow having a highlight presented to a large number of people, such as the ASIMO performance in 2009, but can also include concerts or robot competitions.

This combination of activities, together with a mix of different types of actors and a focus on transmitting enthusiasm for technology, has shown to be a successful format to attract a large number of visitors. Table I shows the evolution of visitors and the importance of the three main activities. 
While every year we conducted surveys to gather feedback from our visitors, in 2011 we performed the largest of them, receiving answers from 3423 visitors. Prior to the festival, people could register on the web for the festival activities; at this occasion they were asked to fill an online form with general questions about age, gender, education, as well as the source of information used to learn about the festival, or their use of robots in daily life. As an incentive to fill this form, every respondent was registered to receive a small robotic gift that was distributed during the day of the festival. A second set of questions was then asked during the festival when people asked for their gift. This second part was more oriented towards the festival activities. Because of the particular conditions of the gifts distribution, only 880 of the 3423 respondants answered to this second set of questions.

This paper presents an analysis of the data collected to understand the profile of the public that was attracted and the festival's impact in the local area. We believe that some patterns could be generalized and give some hints on how to organize this type of events in a successful way.

\section{PROFILE OF VISITORS}

The festival aims at being a very open family event, with many activities for children, contrasting with the perhaps elitist image of a university. Reaching people with a university level education came naturally, as the event is hosted by EPFL, involves several laboratories, and is advertised in the alumni newsletter. In addition, we spread the information through popular newspapers of the region such as 24 Heures, Le Matin and 20 Minutes, which are among the most read newspapers in the french-speaking part of Switzerland. We also had advertisement posters in the city and targeted children via schools by sending them specific information and flyers. Finally, our website provided all the practical information and a dedicated newsletter kept previous years visitors updated about the festival and other similar activities.

\section{A. Visitor's demographic profile}

Based on the answers of 3423 respondents to the online form, the profile of visitors in terms of age and gender is given in Figure 1; percentages are presented in table II. In total, $64 \%$ of the respondents were male, and $36 \%$ female. People of all ages filled the questionnaire, but the low mean age of 23.9 years reflects that more than half of the respondents (54.3\%) were children and teens up to 18 years old. The most represented ages are between 6 and 12 years $(33.7 \%)$ and between 31 and 45 years $(22.7 \%)$. This represents two peaks of generations: parents and their children coming as a family to the festival. We note that in those two peaks there is a high representation of males (66.7\% and $57.8 \%$, respectively), suggesting that there is a tendency to find fathers coming with their son and that a robotics event is more attractive to boys and men. In the age group between those two peaks (19-30 years) there is a larger (45\%) proportion of women. The percentage of men increases then again for ages over 50 (see Figure 1).

The profile of people attending the EPFL robotics festival

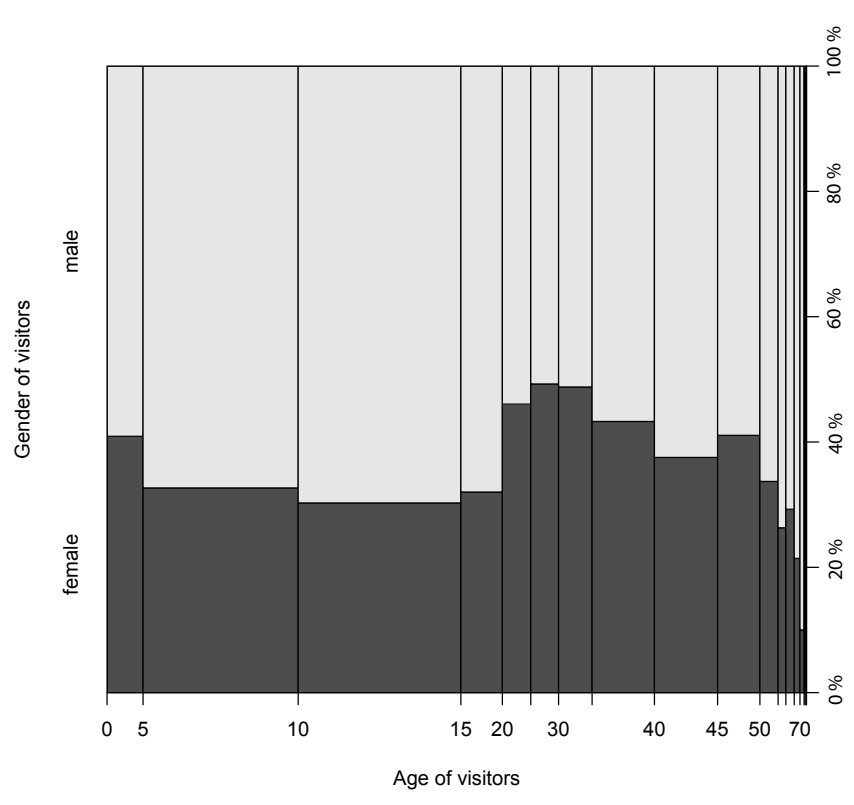

Fig. 1: Age and gender of the visitors of the festival. Data of 3423 people. On the $\mathrm{x}$ axis, the distribution of the scale represents the quantity of people of a given age present at the festival.

TABLE II: Demographic profile of Festival visitors, $\mathrm{N}=3423$, values in percent

\begin{tabular}{|l|l|l|l|}
\hline Age Group & $\begin{array}{l}\text { Females in } \\
\text { age group }\end{array}$ & $\begin{array}{l}\text { Males in } \\
\text { age group }\end{array}$ & $\begin{array}{l}\text { Percent of } \\
\text { total }\end{array}$ \\
\hline 0-5 years & 40.9 & 59.1 & 5.1 \\
6-12 years & 33.3 & 66.7 & 33.7 \\
13-18 years & 27.3 & 72.7 & 15.5 \\
19-30 years & 45 & 55 & 10.1 \\
31-45 years & 42.2 & 57.8 & 22.7 \\
46-60 years & 37.4 & 62.6 & 9.8 \\
61-75 years & 22.5 & 77.5 & 2.6 \\
75+ years & 38.5 & 61.5 & 0.4 \\
average & 36.1 & 63.9 & - \\
\hline
\end{tabular}

is also specific in terms of people's educational background. The distribution illustrated in Figure 2 shows a high proportion of adults (over 24 years old) with higher education degrees. Almost half of the visitors had a university-level degree or a diploma from a university of applied sciences, while the Swiss average for this type of education is is between $20.9 \%$ (women) and $27.6 \%$ (men) ${ }^{1}$. As said before, we expect to have a high popularity among former EPFL students and employees, but also took measures to reach a wider audience through newspapers, posters and advertisement in schools. In general, our data suggests that the topic of the festival and the way in which it was advertised does not attract equally all publics, and thus it cannot fill the goal of spreading efficiently knowledge of technology to people who were not already interested in the field. It reaches currently

\footnotetext{
${ }^{1}$ Statistics of the Swiss Federal Statistical Office, http://www.bfs.admin.ch
} 


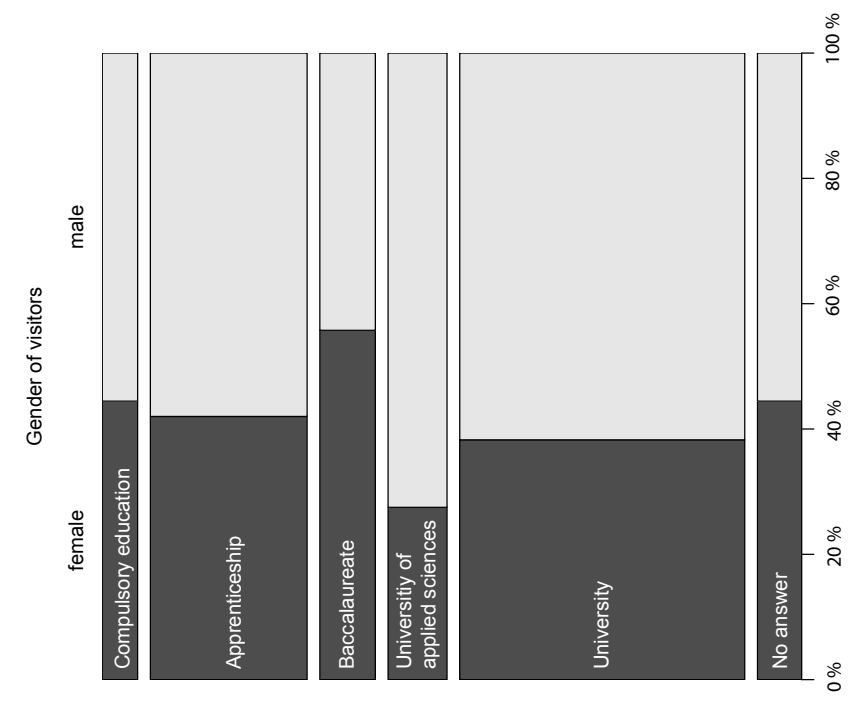

Education of visitors

Fig. 2: Education and gender of the visitors of the festival. Ages over 24. Data of 1294 people.

a specific profile, i.e. rather boys and men, as well as people who completed higher education. Future events will have to adapt their advertising methods and the choice of activities to reach new audiences. Preliminary tests in the advertisement of the workshops have shown that the presentation of the activity has a strong impact on the gender of the participants. Moreover in addition to "classical" activities such as robot competitions, one should encourage innovative approaches to robotics involving cooperation and esthetics. These corrective measures still need to be validated.

\section{B. How people learned about the festival}

To understand which communication channels people used to learn about the festival is crucial, if we want to widen our visitor panel. As mentioned above, we spread the information using newspapers, internet, flyers sent to schools, advertisement posters and newsletters. Almost one third (30.4\%) got to know about the event through the newspapers, followed by friends / colleagues (20\%), and the internet (11.3\%). Our data highlights the importance of friends in the advertisement of the festival, on all age categories, stressing the importance of building a good reputation and keeping the previous visitors updated.

The main information channel as function of the age of the participants is plotted in Figure 3. A statistically significant difference was found in respect to the source of information and the respondent's age group (chi-square $\left.\chi^{2}(N=3423,63)=224.142, p<0.001\right)$. More precisely, with growing age, there was a tendency that respondents more often had heard about the festival through the newspapers and less often through the internet, or from friends / colleagues. Surprisingly, also many children and teenagers

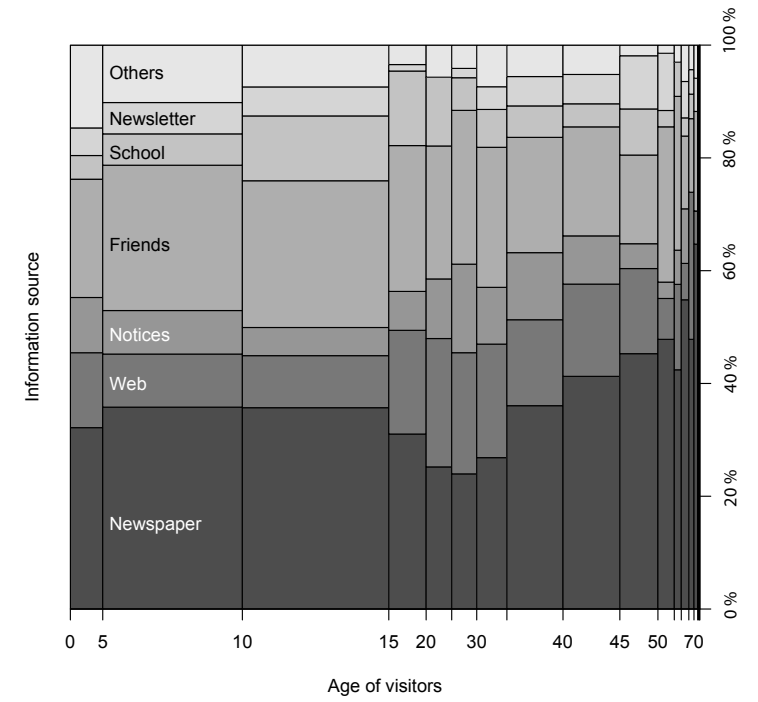

Fig. 3: Source of information about the robotics festival as function of the age of the participants. Data of 2898 people.

TABLE III: How newcomers and re-visitors heard about the festival, $\mathrm{N}=3423$, values in percent

\begin{tabular}{|l|l|l|l|}
\hline $\begin{array}{l}\text { Source of Infor- } \\
\text { mation }\end{array}$ & Newcomers & re-visitors & $\begin{array}{l}\text { Percent of } \\
\text { total }\end{array}$ \\
\hline newspaper & 50.4 & 34.8 & 34.1 \\
friend / colleague & 24.3 & 23.6 & 23.3 \\
Internet & 5.3 & 10.7 & 12.5 \\
poster & 6.6 & 7.2 & 8 \\
school & 5.5 & 8.6 & 7.2 \\
newsletter & 0.9 & 7.4 & 5.6 \\
radio & 1.3 & 0.5 & 1.2 \\
TV & 0.2 & 0 & 0.7 \\
other & 5.3 & 6.9 & 6.8 \\
\hline
\end{tabular}

indicated newspapers as information source, followed by friends, the internet, and school. We assume the impact on the younger age group can be explained by their usage of the free daily newspaper 20 Minutes which is popular among teenagers. Indeed, we noticed a clear impact on the participants' registrations on our website after advertising the festival in this free daily newspaper. The web as a source of information was very popular for the 15-35, and still widely used for the 35-50. It touched less the younger generations, though we expected them to be strong internet users. The newsletter served as information source across all ages and was surprisingly often mentioned by older people.

Moreover, the fact of being a newcomer in contrast to being a re-visitor, had a statistically significant effect on how people heard about the event (chi-square $\chi^{2}(N=$ $3423,18)=118.460, p<0.001)$. More newcomers mentioned the newspapers (50.4\%) and friends (24.3\%) as reference than re-visitors did, who referred as well to the Internet $(10.7 \%)$, school $(8.6 \%)$, the newsletter $(7.4 \%)$, or a poster $(7.2 \%)$ as the source of information (table / Figure 4). In particular, the web page and the e-mail newsletter have been 


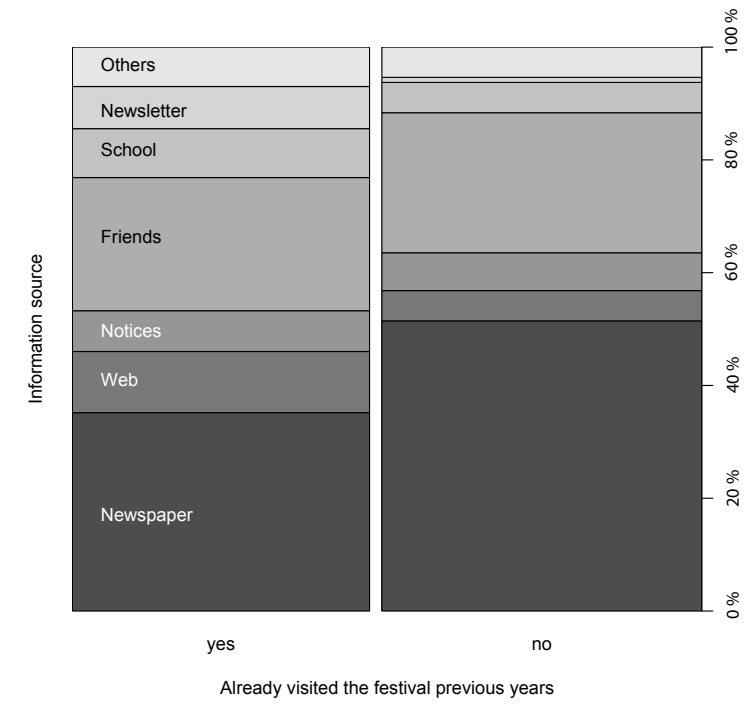

Fig. 4: Source of information about the robotics festival as function of the fact to have already visited the festival in previous years. Data of 873 visitors.

meaningful to the re-visitors. People returning to the festival know the event's website and check it in a regular way, either to look at the program or to register for the activities. The newsletter represents the biggest difference in communication source between newcomers and re-visitors, and is a key tool of the communication strategy of the festival, spreading the information to 1400 registered families.

This highlights the importance of having a diversity of communication channels to advertise such an event to several target audiences. It also show the importance of classical tools such as newspapers and friends in respect to the web, for instance.

\section{ELEMENTS OF IMPACT}

The second part of the survey, conducted during the festival, aimed at understanding the impact of the festival on the visitors. On the one hand, the festival aimed at making robotics accessible to anyone and at encouraging especially younger generations to learn more about science and technology. On the other hand, the survey should give us insights in people's acceptance of robots being artefacts of everyday life and to see how open they would be towards this idea. We present findings in the following.

\section{Interest in robotics and motivation to study engineering}

First, one of the main things we wanted to know was whether the festival had increased chidren's interest for the field of robotics or for technology in general. Visitors were asked to rate several affirmations to target these issues:

- The festival encouraged me to study at EPFL.

- The festival encouraged me to learn more about robotics.

- The festival helped me learn new things about robotics.

\section{- I want to know more about technical sciences.}

Among 535 answers of people younger than 18, 65.8\% answered positively to the first affirmation. This result gives an encouraging view of the festival's impact, as it seems that the festival indeed increases children's interest for engineering. But boys and girls did not answer the same way to this question. The response of boys was nearly $70 \%$ positive, while for girls only $60 \%$ answered yes.

Overall, the gender difference for interest in robotics was statistically significant (chi-square $\chi^{2}(N=2415,2)=$ $8.782, p=0.012)$. In particular, $37.1 \%$ of the male respondents in comparison to $31.4 \%$ of the female respondents indicated the festival encouraged them to learn more about robotics. A similar and as well statistically significant gender difference was found for whether one had the impression the festival helped one to learn more about robots and their usage, or whether it encouraged them to learn more about technologies and science in general. This finding again reflects that future robotic events might aim at approaching girls and women in a particular way since they seem to be less enthusiastic about the topic in general. Additionally, returning visitors tended to be more positive about robotics than newcomers.

We also noticed a correlation between the motivation to study at EPFL and the understanding of what is presented. While $92.5 \%$ of the people younger than 18 said the festival helped them to better understand how robots work, the small minority of people who answered negatively to this question was clearly less motivated to study at EPFL, as illustrated in Figure 5 left. This highlights the importance of how the visitors feel about what they see. If they understand, they are more motivated to be interested in the field and conversely, their interest in the field helps them understand how technology works. This correlation was stronger than between the motivation to study at EPFL and gender, or enjoyment of the festival itself.
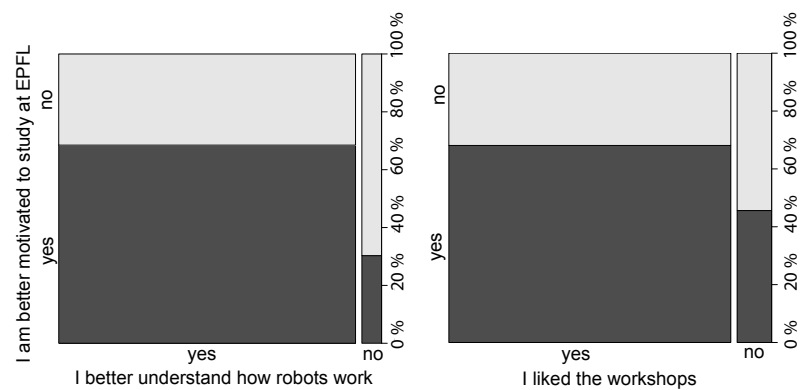

Fig. 5: Relationship between the impression to be better motivated to study at EPFL by the festival and (left, $\mathrm{n}=528$ ) how well the visitors understand robotic mechanisms thanks to the festival and (right, $n=526$ ) the appreciation of the workshops. Ages below 18.

We also thought that the motivation to study at EPFL would be strongly linked to liking the festival and its activities, in particular the workshops. However, as Figure 5 right shows, the correlation with this factor is lower than with 


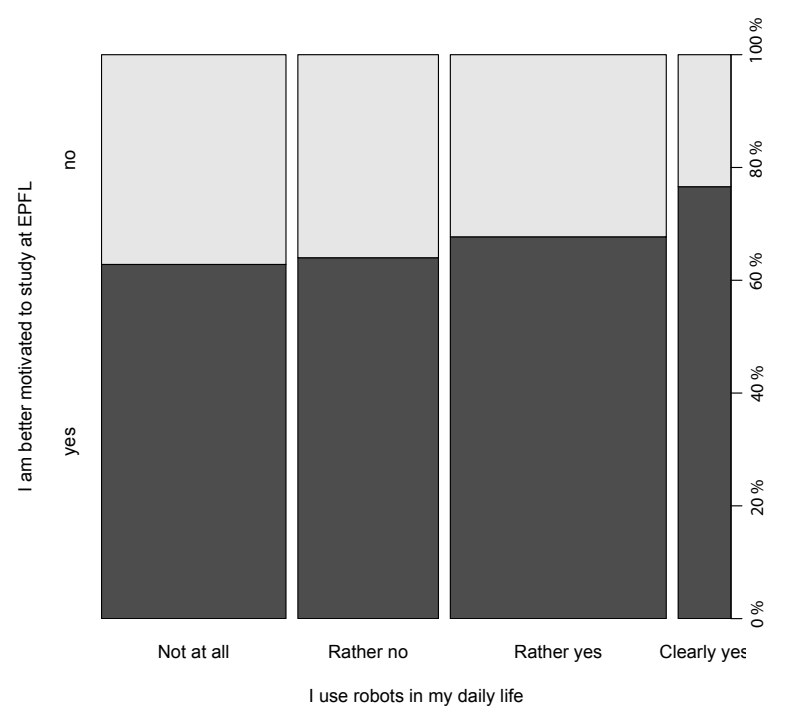

(a)

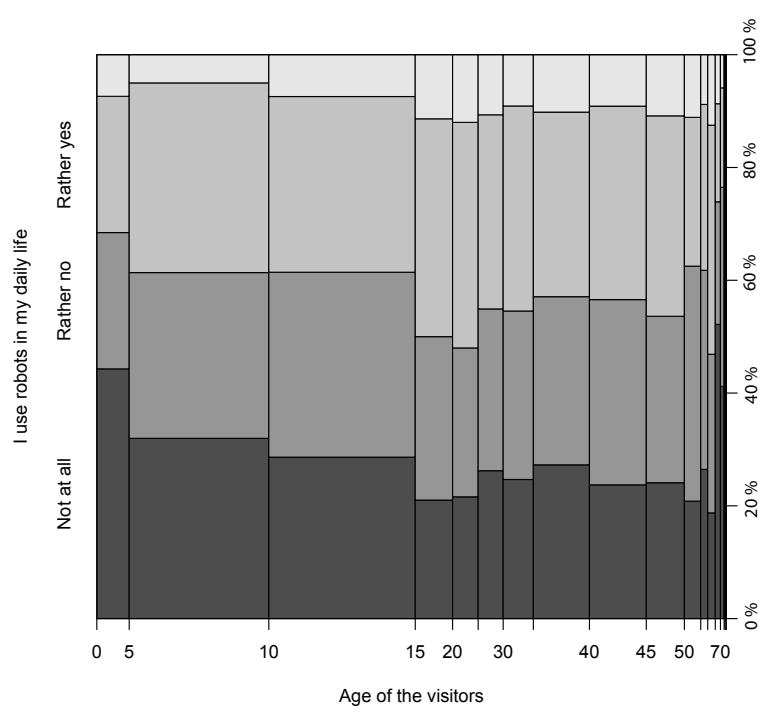

(b)

Fig. 6: (a) Relationship between using a robot in daily life and the impression to be better motivated to study at EPFL by the festival. Ages below 18. $\mathrm{n}=528$. (b) Relationship between age and using a robot in daily life. $\mathrm{n}=877$.

better understanding robotics systems, as shown before.

Another interesting point is that children's answers in how interested they are about robotics seem to be related to whether they had contact to robots already before the festival. Visitors were asked about their use of robots in daily life. The relationship between the answer to this question and the motivation to study at EPFL is shown in Figure 6a for visitors younger than 18 . It has to be noted that the younger visitors are not the most exposed to robots, as illustrated by Figure $6 \mathrm{~b}$.

If we include adults, people's educational background significantly impacted how far they stated to be interested in the field of robotics in their daily life, e.g. regularly reading professional journals about robotics. A chi-square analysis $\left(\chi^{2}(N=3423,4)=68.139, p<0.001\right)$ reveals that people completing the compulsory education answered to less often consult professional journals to read about robotics than people who completed higher education.

Overall, our data shows significant gender differences for the interest in robotics and technology, in terms of sciences as well as reading about those topics in daily life. Further, peoples' educational background as well as their previous experience with robots seem to play a role. A similar profile was described for people using a domestic vacuum cleaning robot in the U.S. [8]. Our data also suggests that children are better motivated in the field if they feel they understand the mechanisms of robotics.

\section{CONCLUSIONS AND FUTURE WORKS}

\section{A. Conclusions}

Science festivals are a very nice form of involvement of the public in science and technology and help in making a link between professionals in the field and young generations. Their flexible format allows a diversity of activities which is important to increase the interest for the scientific and technological topics. This variety of exhibits and activities gathered in one place over a few days, or even a single one, is very attractive to families. The EPFL robotics festival is such an example. In few years it became a major robotics event in Switzerland attracting between 10'000 and 15'000 visitors on a single day. Here are the key factors we could observe, for making a successful event:

Diversify the activities to make it an open, family event: Thanks to a variety of exhibits and shows for everyone and a special emphasis on making a great experience for children with the workshops, we managed to attract people of all ages. However, we still observe a majority of visitors who completed higher education and a dominance of males. While the rate of women and girls has been continuously growing in the last festival editions, the result is still not satisfactory and needs to be improved. Concerning the education of the parents, the weak presence of families having a lower education background should also be corrected. To achieve this goal and reach a wider spectrum of people we will continue adapting our message and advertising campaign toward females and families with a lower education background. This can be done for instance by involving more non-engineering women into the festival organization, better using free newspapers that are widely spread and attract children directly with free gifts distributed during the festival.

Use many communication channels: Newspapers and advertisement posters allow to inform new potential visitors while websites and newsletter keep the previous years visitors informed. Several popular newspapers were used and 
allowed to reach people above 35 , but also teenagers who read the free newspapers. Having all information available on the Internet is really appreciated among the 15-35.

The impact of some specific channels has to be studied in detail and strongly depends on the implementation, but this suggest that having a variety of channels is primordial to advertise such an event.

Build a reputation: As said above, dedicated channels such as newsletters and websites allow to maintain the link with the previous year's visitors, who are key players in propagating the information to their friends or colleagues. We also benefited from the reputation of EPFL itself, as many current or former EPFL students and employees visited our event and spread the word. We were careful though to avoid giving an elitist image that is sometimes linked to universities to not discourage visitors.

Have a variety of exhibits by passionate people: To be accepted at our festival, exhibitors must have a live demonstration. We tried to have exhibitors of several backgrounds, from industry to research, not forgetting passionate hobbyists or artists. In this study, we saw that the visitors like to understand what is presented, and that this is a key factor influencing other aspects such as interest for engineering education. More than the simple enjoyment of the event, the visitor's feeling to have learned about and understood the mechanisms underlying science and technology will influence their opinions and interest. This reflects some empirical observation we made during the festival: it is better to present basic or rickety robots with a good explanation by an enthusiastic person than presenting a well-performing robot without the possibility of understanding how it works.

\section{B. Future Works}

This study highlighted the difference of interest in the topic of robotics between men and women. Some specific analysis needs to be carried out to address the gender issue, in order to better attract women and girls, now only $30 \%$ of the workshops participants. In the future we will aim at approaching them in a different way, to break the masculine image of robotics. We will also try new communication channels to reach more people who don't have a university background, and improve our communication methods to enhance the open, accessible image of our event.

We saw the contact with robots has also an impact on children and their interest for engineering. While this will happen naturally with the dissemination of domestic robots, the distribution of educational robots could be a key aspect to motivate younger generations. This has been a central activity of the robotics festival, where several workshops allow building or programming robots that can be taken home, and this activity will be pursued.

\section{ACKNOWLEDGMENTS}

This research as well as the festival organization itself was supported by the Swiss National Science Foundation through the National Centre of Competence in Research Robotics.

\section{REFERENCES}

[1] M. Shiomi, T. Kanda, H. Ishiguro, and N. Hagita, "Interactive humanoid robots for a science museum," in Proceedings of the 1st ACM SIGCHI/SIGART conference on Human-robot interaction, ser. HRI '06. New York, NY, USA: ACM, 2006, pp. 305-312. [Online]. Available: http://doi.acm.org/10.1145/1121241.1121293

[2] T. Shibata, K. Wada, and K. Tanie, "Subjective evaluation of a seal robot at the national museum of science and technology in stockholm," in Robot and Human Interactive Communication, 2003. Proceedings. ROMAN 2003. The 12th IEEE International Workshop on, oct.-2 nov. 2003 , pp. $397-402$.

[3] C. Messom, D. Carnegie, P. Xu, S. Demidenko, and D. Bailey, "Robotic competitions: Motivation for engineering programmes," in Proceedings of the Ninth New Zealand Electronics Conference, Dunedin, Dunedin, New Zealand, 2002, pp. 55-60.

[4] H. Kitano, S. Suzuki, and J. Akita, "Robocup jr.: Robocup for edutainment," in Robotics and Automation, 2000. Proceedings. ICRA 'O0. IEEE International Conference on, vol. 1, 2000, pp. 807 -812 vol.1.

[5] D. Oppliger, "Using first lego league to enhance engineering education and to increase the pool of future engineering students (work in progress)," in Frontiers in Education, 2002. FIE 2002. 32nd Annual, vol. 3, nov. 2002, pp. S4D-11 - S4D-15 vol.3.

[6] M. Asada, R. D'Andrea, A. Birk, H. Kitano, and M. Veloso, "Robotics in edutainment," in Robotics and Automation, 2000. Proceedings. ICRA 'O0. IEEE International Conference on, vol. 1, 2000, pp. 795 -800 vol.1.

[7] E. Nakano, M. Asada, S. Tadokoro, K. Osuka, K. Nagai, Y. Masutani, and H. Kitano, "The outline of the international robot games festival," in Robotics and Automation, 2000. Proceedings. ICRA 'O0. IEEE International Conference on, vol. 1, 2000, pp. 820 -825 vol.1.

[8] J. Sung, R. Grinter, H. Christensen, and L. Guo, "Housewives or technophiles?: understanding domestic robot owners," in Proceedings of the 3rd ACM/IEEE international conference on Human robot interaction. ACM, 2008, pp. 129-136. 